\title{
ENGAGEMENT AND INVOLVEMENT OF PERSONNEL DURING REMOTE WORK
}

\section{Solveiga Blumberga ${ }^{1}$, Laura Lapkovska $^{2}$}

\begin{abstract}
The COVID-19 pandemic has altered the majority of the world's organisations through making remote work a part and parcel of everyday life. The number of people working remotely has increased substantially creating a challenge for the organisations to manage and involve their personnel. Engagement and involvement of the personnel are major factors contributing to a positive outcome of the remote work processes. The aim of this research paper is to establish what the engagement and involvement of the personnel are while practising remote work in the Latvian financial institutions. This research paper put forward the following issues for exploration: what is the engagement of the financial institutions' personnel in their work while working remotely? What is the involvement of the financial institutions' personnel in their work while working remotely? Is there a link between engagement and involvement of the financial institutions' personnel during remote work? This paper explores the definitions of engagement and involvement by various authors and many forms of remote work putting emphasis on expansion of remote work due to the pandemic. The research made use of 3 surveys: a survey on the engagement of personnel during remote work, a survey on involvement of the personnel during remote work and a survey on the personnel's opinion on remote work compiled by the authors of this research paper. There were 98 full-time employees of financial institutions participating in the research who were transferred from office jobs to a form of remote work during the COVID-19 pandemic. The results of the research demonstrate that only a fraction of the financial institutions' personnel were engaged and involved during their remote work and that institutions had to resort to additional measures in order to promote involvement and engagement of the rest of the personnel and attain better operational results. The major problems highlighted by the results of the research are: insufficient internal information exchange and co-operation. The personnel feel responsible for the performance of their work, but admit to lacking inspiration that would foster their engagement. They also acquired negative experiences while working remotely. The results of the research identify a need for further research on the significance of the internal culture and communication of financial organisations for the promotion of involvement and engagement of personnel during remote work.
\end{abstract}

UDC Classification: 331.1, DOI: https://doi.org/10.12955/pss.v2.201

Keywords: employee engagement; employee involvement, remote work.

\section{Introduction}

\section{Engagement of Personnel}

Research by Gallup demonstrates that in their drive for the planned operational results, the companies that lay great emphasis on satisfying people's need for psychological engagement achieve the best results. At the same time $85 \%$ of the world's employees do not feel engaged in work which is a very disturbing figure. In total only $15 \%$ of the workforce perform their duties with full dedication, personal involvement and assurance of their assignments, when the rest of the employees perform their merely out of sense of duty and to receive the remuneration. The Gallup research highlight the huge potential of the personnel engagement factor that every company and business manager should seriously consider in order to improve and maximise the overall operational results of the organisation (Gallup, 2017).

The Aberdeen Group defines employee engagement as the personnel's positive work-related attitude that is characterised by a high energy level, emotional commitment and satisfaction created by work which most likely will be successfully reinvested in the company with the employees working more on the improvement of the company's income and reputation (White, 2016).

Kris Kitto (2019) points out that a recent report by the Analytical Services of Harvard Business Review established that three quarters of surveyed business executives strongly agreed that the personnel who were engaged in work most likely demonstrated high individual performance. The organisations where the personnel were engaged in work also have better financial health as these organisations have a more productive workforce.

Engagement of personnel implies that the company has created conditions that enable the personnel and make them willing to input more of their energy, abilities and potential into their work. Sinclair also notes that each company has its own unique ways or formulas on how to increase personnel engagement (Sinclair, 2020).

Alongside the raising of the personnel's engagement level, companies acquire greater productivity and decreased personnel turnover as employees feel no need to search for new workplaces when they are being valued and have development options right where they are- Additionally, engagement of the

\footnotetext{
${ }^{1}$ RISEBA University, Business Department, Riga, Latvia, solveiga.blumberga@ @riseba.lv

${ }^{2}$ RISEBA University, Riga, Latvia, laura.lapkovska@gmail.com
} 
personnel promotes customer satisfaction since the personnel perform their duties as best as they can. Moreover, health of employees improves which is explained by a more positive and inclusive working environment. In addition to the observed benefits there is a reduction in the number of occupational injuries mostly due to the personnel being focused on their duties and performing their roles with conscientious return. Finally, time spent on a sick leave decreases, and, taken together, this all cuts the financial costs of the company (Ryba, 2020).

\section{Involvement of Personnel}

Regarding employee involvement, the American Psychological Association finds in its survey that less than two-thirds $(64 \%)$ of the respondents are satisfied with the possibilities offered by their company to get involved in decision-taking, problem solving and the setting of targets, but only half claim that they are involved in these essential activities on a regular basis (American Psychological Association, 2012). The organisations that think and plan in the long-term achieve the best results. By long-term planning the following is meant - to do more, especially in terms of the working environment experience of the personnel, than the current situation requires from the company so that, as a result, people would come to work not because they have to, but because they want to (Morgan, 2017). This indicates that not only the personnel have to go an extra mile, but already from the beginning the employer has to thoroughly consider the environment where the personnel will have to work - about its values and targets, so that this physical, cognitive and emotional environment is unified and stimulates positive feelings and results.

One of the models for personnel involvement in a company includes certain actions of the company that foster an increase in the level of personnel involvement. These actions increase the importance of the role of the personnel in the company's day-to-day work (Heathfield, 2019).

\section{Remote Work}

Due to the COVID-19 pandemic (in year 2020), remote work became a survival tool for many companies, including the financial sector of Latvia, ensuring operational continuity. For many companies of the financial sector the sudden onset of the remote work form brought about the challenge of ensuring operational continuity and risks of being unable to sustain office work or replace it with remote work. Given that remote work has not been a daily occurrence for the Latvian financial companies and people were not prepared for such a change in the form of work, a common dialogue on the topic is very important for both employers and personnel to implement the new work format as successfully as possible and on mutually acceptable terms.

On most occasions remote work exerted a positive impact on the balance of work/personal life reducing the possibility of conflict regarding time allotted to work and family. However, if the remote work exceeds 2.5 days a week, the impact of remote work on relationships with co-workers is more detrimental and rather has a negative effect (Gajendran \& Harrison, 2007).

The spread of COVID-19 changed the rules of the game swiftly and starting from September 2020 nearly $40 \%$ of full-time employees were working only from their homes (compared to $4 \%$ before COVID-19) (Wigert \& Robson, 2020). Additionally, the companies of the Latvian financial sector had to adapt in very little time and start practising remote work. The present personnel management processes are unsuitable, and several problems have come to light, like informing of the personnel, isolation, and involvement of the personnel.

The authors of this research paper wanted to study involvement and engagement in the remote work of mid-level personnel of Latvian financial companies who had not practised remote work before the COVID-19 pandemic.

\section{Methods}

The strategy of a quantitative study was chosen for the research. Three surveys were used for the acquisition of primary data: Utrecht Work Engagement Scale (UWES) (Schaufeli \& Bakker, 2004) consisting of 3 survey scales: Vigor, Absorption, and Dedication along with 17 questions; Job Engagement Scale (JES) (Rich, LePine \& Crawford, 2010) consisting of 3 survey scales: Physical involvement, Emotional involvement and Cognitive involvement along with 18 questions; and a survey compiled by the authors of this research paper on the personnel's opinion on remote work consisting of 4 scales: Employee satisfaction, Internal communication, Work intensity/work load, and their Emotions 
along with 17 questions. The research questions were the following: what is the engagement of the financial institutions' personnel in their work while working remotely? What is the involvement of the financial institutions' personnel in their work while working remotely? Are there statistically significant correlations between the ratings of engagement and involvement of the financial institutions' personnel during remote work? The general sample of the study consists of mid-level personnel of the Latvian financial sector aged from 20 to 61 years old, working in Riga, whose principal employment before the COVID-19 pandemic was in the office, but changed to a remote work format in 2020. In compliance with the General Data Protection Regulation the survey was sent to the respondents that reacted to a call for taking part in a survey published over the Internet platform. By making calculations to verify the sufficiency of the sample, it has been determined that the study sample, $\mathrm{N}=98$, was sufficient. Assuming a possible error of $6.3 \%$, the credibility of the results is $90 \%$. (Authors used a Sample size calculator: with sample size - 98, population size - 225 (15 the biggest banking/finance sector players in Riga, if in general each of them has 15 units or 15 mid-level managers each).

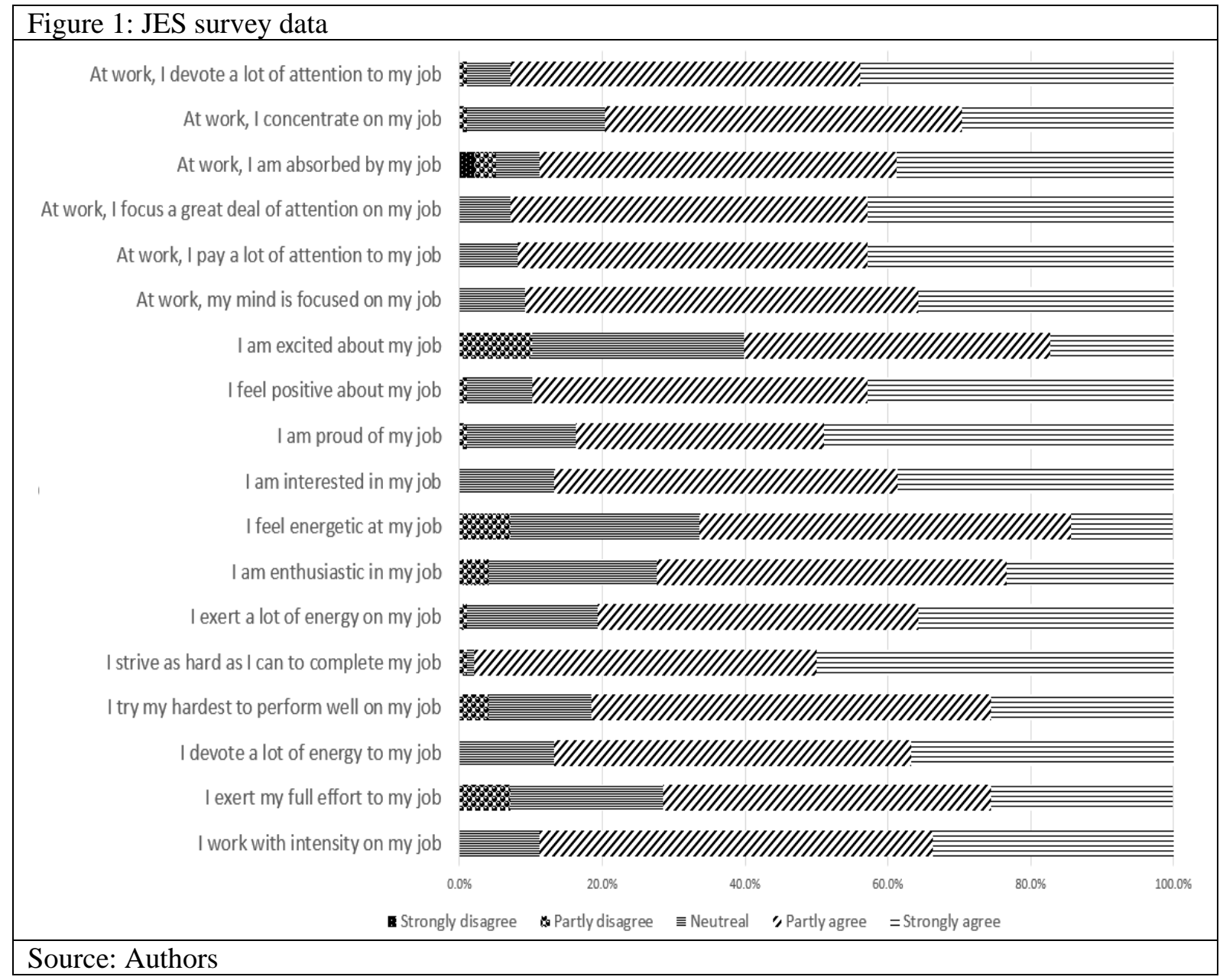

\section{Results}

In the Physical involvement scale $7 \%$ of the respondents indicate that they partly disagree with the assertion that they devote all efforts to the job, but $21 \%$ of the respondents cannot tell whether they devote all efforts to the job or not. Nevertheless, $71 \%$ of the respondents devote all their efforts to the job. $98 \%$ of the respondents either strongly agree or partly agree that they strive as hard as they can to always complete the job which is a very significant factor for achievement of results. In the Emotional involvement scale $49 \%$ of the personnel say that they are proud of their job and $43 \%$ admit that they also felt positive about their job. It is an excellent foundation for spreading of the company's positive references outside the working environment and creates the sense of personal involvement and of being a part of positively appraised work that one can take pride in. Nevertheless, this indicator should be increased through the promotion of personal involvement of the employees, possibly by resorting to greater autonomy in decision-making and action. Meanwhile 7\% of the respondents replied that they 
did not feel energetic and $4 \%$ - were not enthusiastic about their job and testified to existence of dullness in their performance of everyday duties. Moreover, $10 \%$ of the personnel partly disagree with the assertion 'I am excited about my job' that points to internal structure problems or a lack of explanations and trust. In the Cognitive involvement scale $91 \%$ (the sum total of 'strongly agree' and 'partly agree') focused a great deal of attention on their job, while $88 \%$ paid a lot of attention to their job which is a very good indicator for maximum efforts being input into achieving the set aims as high concentration on the role secures adequately directed energy.

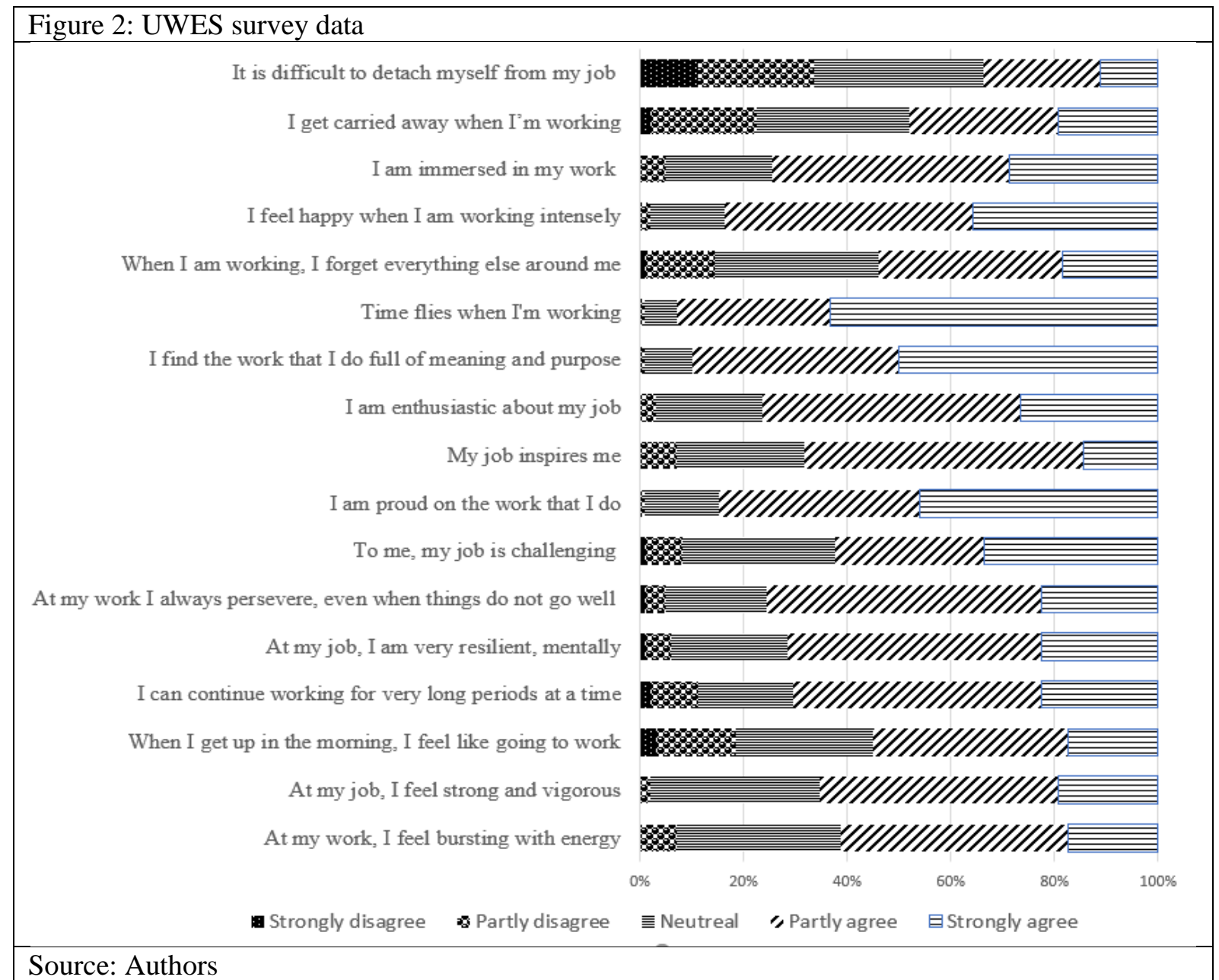

In the Vigor scale, $7 \%$ of the respondents partly disagree with the assertion that they feel energetic about their job and 32\% cannot provide neither affirmative nor negative answer as to their energy levels which coupled with inattentiveness of the management may result in an increase in disinterested personnel lacking energy that, in its turn, will impact productivity of the financial company. $15 \%$ of the respondents partly disagreed with the assertion 'When I get up in the morning, I feel like going to work', but 3\% - strongly disagreed. The personnel do not feel like devoting themselves to work - which is important for the personnel to act productively and with full dedication while functioning in their job roles. Despite $9 \%$ of the respondents partly disagreeing and $2 \%$ strongly disagreeing with being able to continue working for very long periods of time, the majority can do it and, if need be, accomplish the projects. In the Dedication scale $50 \%$ of the respondents strongly agree and $40 \%$ partly agree with the assertion that 'I find the work that I do full of meaning and purpose' which is a very significant factor for the personnel to carry out their work with responsibility and understanding of its essence that, in its turn, promotes productivity and quality in the accomplishment of tasks. $46 \%$ of the respondents indicate that they strongly agree with being proud of what they do and 39\% - partly agree with this assertion which, taken together, is a very good indicator to assume that the majority of the personnel understand the common values and mission of their work, that supports a joint understanding and vision of the future and the development of the company. In the Absorption scale 13\% of the respondents partly disagree with the assertion that the personnel forget everything around them when working and $20 \%$ of 
the respondents partly disagree with the assertion that personnel are immersed in work which points to the attention capacity of the personnel and possibly other factors distracting attention. $63 \%$ of the respondents say that time flies when working. In total $33 \%$ of the respondents reject ('strongly disagree' and 'partly disagree') the assertion that it would have been difficult to detach themselves from their role/work which makes one reflect on work as the pivotal interest in life and shows a complete fusion with one's daily role or identification with one's role at work.

The results of the Internal information scale demonstrate that $30 \%$ of the respondents encounter problems with information exchange and approximately $24 \%$ encounter information exchange problems exactly at the level of structural units. The Workload scale reveals that although only $13 \%$ of the respondents emphasize that they do not work longer hours during remote work, the workload has not increased for $39 \%$ - with personnel devoting more time to their daily duties rather than the proactive addressing of issues or the more diligent performance of their work role. The scale of Emotions shows that $54 \%$ of the personnel feel decreased stress while working remotely and $66 \%$ feel cheerful which promotes a positive attitude, helping to tackle their daily duties in a more logical and positive way. Companies have to think more about adapting the remote work format to their employees by eliminating the possible negative obstacles since roughly half of the respondents perceive this format as a bonus. Hence, remote work could be used not only as a forced format, but also as a positive stimulus provided companies could find ways how to increase the comfort and satisfaction of remote work while keeping in mind the involvement and engagement factors that would allow companies to get greater productivity and help them achieve their aims.

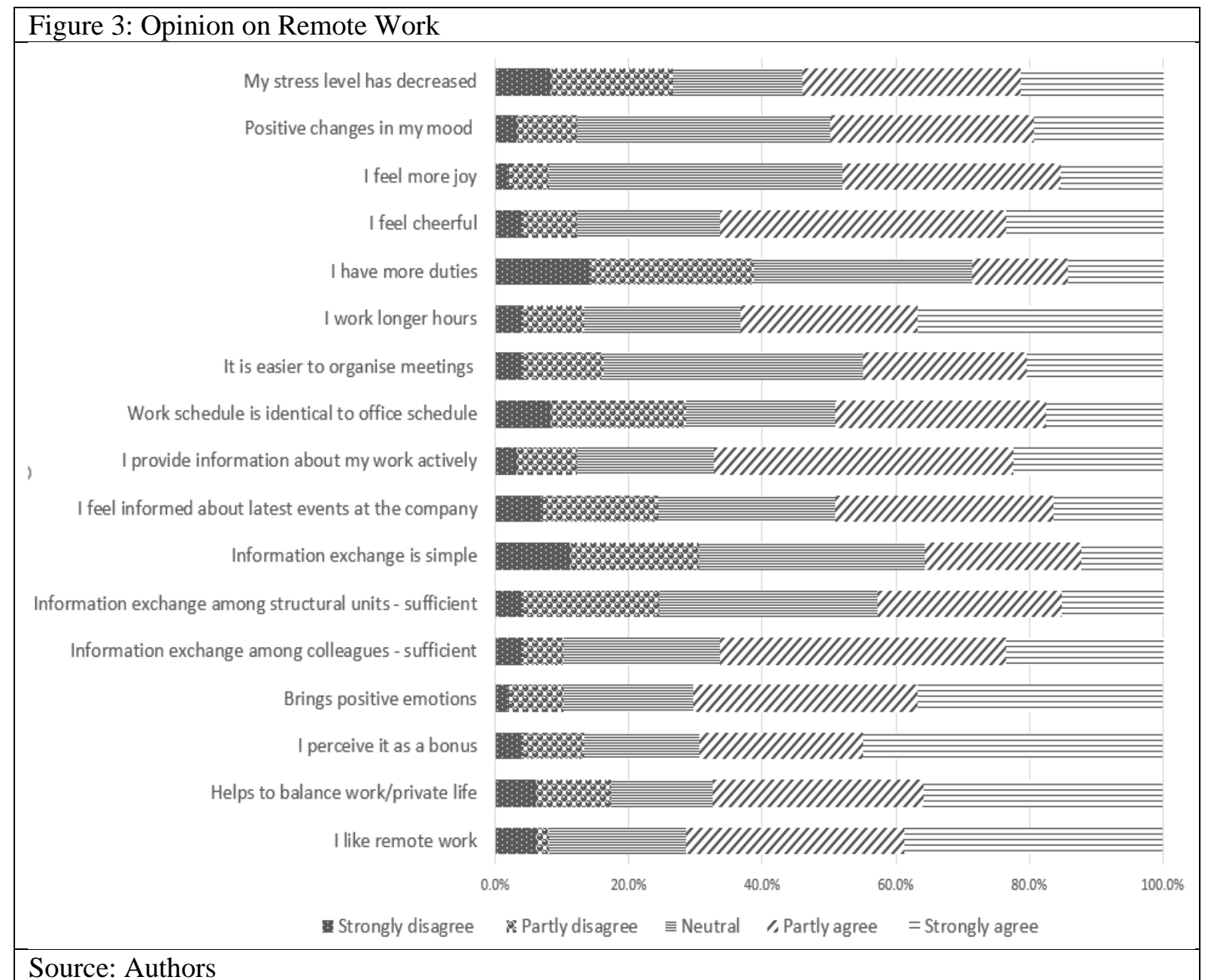

There is a statistically significant positive correlation in the reflection of correlation indicators between the UWES survey scales of Vigor, Dedication, and Absorption and the JES survey scales of Physical involvement, Emotional involvement and Cognitive involvement, as the level of bilateral significance is less than 0.01 in all scale combinations. This means that the greater the Physical involvement, the larger the Absorption, Dedication, and Vigor, and vice versa. 
It can be deduced that there is a mutual positive coherence with Emotional involvement - the greater the Emotional involvement, the greater the Vigor, Dedication and Absorption, and vice versa.

Likewise, there is a positive coherence among Cognitive involvement and Vigor, Dedication and Absorption - the greater the Cognitive involvement, the greater the Vigor, Dedication and Absorption, and vice versa (see Figure 1):

There is a statistically significant positive correlation between the scales of Physical involvement and Vigor $(r=.474$ and $\mathrm{p}=0.000)$ which means that with an increase in the work energy of the personnel, there is also an increase in the personnel's physical well-being and uplift about their work, and vice versa. A very similar statistically significant correlation exists between the scales of Physical involvement and Dedication and the scales of Physical involvement and Absorption ( $r=.456, p=.000$ and $\mathrm{r}=.588, \mathrm{p}=.000$ respectively). This means that the more attention and concentration the personnel devote to the job and take pride in what they do, the greater their physical well-being and physical energy is for performing their duties and vice versa.

Also, the Emotional involvement scale has a statistically significant positive correlation with the scales of Vigor, Dedication and Absorption. The more the personnel are emotionally involved in their job, the more energy they have to devote to their tasks, and the more energy they devote, the greater their pride in their job, the greater their self-confidence, the more enthusiastic they are at work, the faster the time flies and vice versa.

\begin{tabular}{|c|c|c|c|c|}
\hline \multicolumn{6}{|c|}{ Table 1: Calculation of Pearson's Correlation Coefficient for UWES and JES } \\
\hline & & Vigor & Dedication & Absorption \\
\hline \multirow{2}{*}{$\begin{array}{c}\text { Physical } \\
\text { involvement }\end{array}$} & Pearson's Correlation & $0.474^{* *}$ & $0.456^{* *}$ & $0.588^{* *}$ \\
\cline { 2 - 5 } & Sig. (2-tailed) & 0.000 & 0.000 & 0.000 \\
\hline $\begin{array}{c}\text { Emotional } \\
\text { involvement }\end{array}$ & Pearson's Correlation & $0.769^{* *}$ & $0.807^{* *}$ & $0.527^{* *}$ \\
\hline \multirow{2}{*}{$\begin{array}{c}\text { Cognitive } \\
\text { involvement }\end{array}$} & Sig. (2-tailed) & 0.000 & 0.000 & 0.000 \\
\cline { 2 - 5 } & Pearson's Correlation & $0.515^{* *}$ & $0.431^{* *}$ & $0.552^{* *}$ \\
\hline
\end{tabular}

Source: Authors

Regarding the UWES scale and the scales of the survey compiled by the authors of this research paper, there is a statistically significant positive correlation detected between the scales of Vigor and Internal communication ( $\mathrm{r}=.319$ and $\mathrm{p}=.001)$ (see Figure 2). This means that the more Internal mutual communication there is, the higher the level of Vigor, and vice versa. This correlation is related to personnel being informed about their work, duties and the company. The better the understanding and knowledge the personnel have about the state of affairs of their company, the greater the personnel's vigor and energy is for the performance of their duties. Also, greater vigor and invested energy lead to more internal communication. Mutual knowledge is generated during this process, the more the personnel work, the more information exchange they have.

A statistically significant positive correlation is observed between the scales of Workload and Vigor the larger the Vigor, the larger the Workload, and vice versa $(\mathrm{r}=.205, \mathrm{p}=.043)$. The authors of this research paper point out that the correlation of these scales indicates that there is a close link between the workload or amount of responsibilities and the energy devoted to work, and vice versa - if the employee is energetic and physically able to accomplish a lot, then the amount of responsibilities will increase. The more you can do, the more you will get.

A statistically significant positive correlation is observed also between the scales of Dedication and Workload ( $\mathrm{r}=.325, \mathrm{p}=.001)$. The personnel dedicated to work are enthusiastic about what they do, take on more responsibilities and work longer hours during remote work, and vice versa. The more a person does and engages in their duties, the greater the sense of belonging and pride they acquire through their dedication to work.

Also, there is a statistically significant positive correlation between the scales of Absorption and Workload ( $\mathrm{r}=.288, \mathrm{p}=.004)$. This can be explained by the fact that absolute concentration on work by the personnel and being immersed in work to the extent that time flies when working promote a greater workload during remote work, and vice versa. 


\begin{tabular}{|c|l|c|c|c|c|}
\hline \multicolumn{2}{|c|}{ Table 2: Calculation of Pearson's Correlation Coefficient for UWES and the Authors' Survey } \\
\hline \multirow{2}{*}{ Vigor } & Satisfaction & $\begin{array}{c}\text { Internal } \\
\text { communication }\end{array}$ & Workload & Emotions \\
\hline \multirow{2}{*}{ Dedication } & $\begin{array}{l}\text { Pearson's } \\
\text { Correlation }\end{array}$ & 0.144 & $0.319^{* *}$ & $0.205^{*}$ & 0.142 \\
\cline { 2 - 6 } & Sig. (2-tailed) & 0.157 & 0.001 & 0.043 & 0.164 \\
\hline \multirow{2}{*}{ Absorption } & $\begin{array}{l}\text { Pearson's } \\
\text { Correlation }\end{array}$ & 0.182 & 0.172 & $0.325^{* *}$ & 0.184 \\
\cline { 2 - 6 } & Sig. (2-tailed) & 0.072 & 0.090 & 0.001 & 0.070 \\
\cline { 2 - 6 } & $\begin{array}{l}\text { Pearson's } \\
\text { Correlation }\end{array}$ & 0.069 & 0.069 & $0.288^{* *}$ & -0.023 \\
\hline
\end{tabular}

Source: Authors

The correlation of the scales of the JES survey with the scales of the authors' survey highlights a statistically significant positive correlation between the scales of Satisfaction and Physical involvement, the scales of Internal communication and Physical involvement and the scales of Workload and Physical involvement.

There is a statistically significant positive correlation between the scales of Physical involvement and Satisfaction with remote work $(\mathrm{r}=.205, \mathrm{p}=.043)$. The authors indicate that this correlation demonstrates that the personnel's physical energy, uplift and enthusiasm about their work also promote satisfaction when working remotely and vice versa. Also, there is a positive correlation among Emotional involvement and all scales of the remote work survey, but the Cognitive involvement scale correlates positively with the scales of Internal communication, Workload and Emotions from the survey on the personnel's opinion of remote work.

A statistically significant positive correlation is observed also for these scales: Physical involvement and Internal communication $(\mathrm{r}=.349, \mathrm{p}=.000)$. This is due to the fact that the more efforts the personnel put into their work and are physically uplifted about the work, the more the personnel are inclined to engage in mutual information exchange, also when working remotely, and vice versa. A similar statistically significant positive correlation exists between the scales of Physical involvement and Workload $(\mathrm{r}=.520, \mathrm{p}=.000)$. The personnel's enthusiasm and efforts devoted to work increase their workload during remote work and vice versa. The greater their workload when working remotely increases the effort put into work.

\begin{tabular}{|c|c|c|c|c|c|}
\hline & & Satisfaction & $\begin{array}{c}\text { Internal } \\
\text { communication }\end{array}$ & Workload & Emotions \\
\hline \multirow{2}{*}{$\begin{array}{l}\text { Physical } \\
\text { involvement }\end{array}$} & $\begin{array}{l}\text { Pearson's } \\
\text { Correlation }\end{array}$ & $0.205^{*}$ & $0.349^{* *}$ & $0.520^{* *}$ & 0.078 \\
\hline & Sig. (2-tailed) & 0.043 & 0.000 & 0.000 & 0.442 \\
\hline \multirow{2}{*}{$\begin{array}{l}\text { Emotional } \\
\text { involvement }\end{array}$} & $\begin{array}{l}\text { Pearson's } \\
\text { Correlation }\end{array}$ & $0.293^{* *}$ & $0.224^{*}$ & $0.323^{* *}$ & $0.282^{* *}$ \\
\hline & Sig. (2-tailed) & 0.003 & 0.026 & 0.001 & 0.005 \\
\hline \multirow{2}{*}{$\begin{array}{l}\text { Cognitive } \\
\text { involvement }\end{array}$} & $\begin{array}{l}\text { Pearson's } \\
\text { Correlation }\end{array}$ & 0.193 & $0.281^{* *}$ & $0.370^{* *}$ & $0.232^{*}$ \\
\hline & Sig. (2-tailed) & 0.056 & 0.005 & 0.000 & 0.021 \\
\hline
\end{tabular}

The Emotional involvement scale has a statistically significant positive correlation with all scales of the author's survey (Satisfaction, Internal communication, Workload and Emotions) - see ' $r$ ' and 'p' indicators in Figure 3. It confirms the role of Emotional involvement in the personnel's Satisfaction with remote work, their Internal communication during remote work, the impact of Workload and their Emotional status. An increase in the indicators of the Emotional involvement scale brings about an increase in the indicators of other scales as well.

No correlation has been detected between the scales of Physical involvement and Emotions and the scales of Cognitive involvement and Satisfaction. 


\section{Conclusions and Recommendations}

The research demonstrates that the majority of respondents (80\%) feel involved during remote work, which confirms that they put every effort into their work. $91 \%$ of the respondents are focused on their duties, $88 \%$ - devote a great deal of attention to their duties. This implies that a high concentration on their work role secures an adequate channelling of their energy. $30 \%$ of the respondents admit to having information exchange problems while working remotely which points to insufficient information exchange and involvement within the organisation. Most of the respondents (70\%) were engaged while working remotely suggesting that the respondents find the job they do full of meaning. $80 \%$ of the respondents are proud of the job they do, implying that they understand and accept the aims and values of their work. $20 \%$ of the respondents say that they are unwilling to devote themselves to work demonstrating that they are not engaged and do not give their full effort to their job. There is a statistically significant positive correlation between engagement and the involvement of the personnel in their work while working remotely which implies the more the personnel are engaged, the more the personnel appreciate their involvement in their work, and vice versa. The more the management involve the personnel, the more they engage themselves in remote work. While working remotely the major problems regarding engagement and involvement of the financial institutions' personnel are insufficient internal information exchange and mutual co-operation (of the structural units), including receiving feed-back from the management. The personnel have a sense of duty and dedicate themselves to work consciously, however they do not see it as their calling, they lack inspiration and positive energy, a collective bond. During remote work 1/4 of the personnel have acquired a negative experience when working remotely (stress, shortage of information, communication format and skills for management/compliance with remote processes, or an uneven workload).

The financial companies must elaborate a format of creating internal publicity and explaining company's achievements to the personnel so that they are informed of achievements and results as well as actions to be undertaken to attain their set goals. It would be useful to organize extended personnel and management meetings to discuss current and future issues and receive feedback and assessment so as to make the personnel feel valued, informed, and have constructive and open communication. The heads of the structural units should practice coaching when leading their subordinates. Also, daily online meetings are of utmost importance for uniting the personnel and exchanging information so that all the personnel can meet up, and hence, compensate for the physical isolation of remote work. The company management should undertake measures to more involve and encourage the involvement of personnel in the exchange of ideas and suggestions that could improve substantially the processes, quality of products and form a deeper understanding of the operations of the company for the personnel. Daily workload measurements are of critical importance to identify the points of overwork in the structural units to avoid overwork and burn-out of some employees and ensure a smooth flow of responsibilities during remote work.

\section{References}

American Psychological Association (2012). Workplace Survey[PDF file]. Retrieved from https://www.apa.org/news/press/releases/phwa/workplace-survey.pdf

Gajendran, R. S., Harrison, D. A. (2007). The good, the bad, and the unknown about telecommuting: Meta-analysis of psychological mediators and individual consequences. Journal of Applied Psychology. Vol. 92, No. 6, 1524-1541 DOI: 10.1037/0021-9010.92.6.1524

Gallup, 2017. State of the Global Workplace. Retrieved from https://www.slideshare.net/adrianboucek/state-of-the-globalworkplace-gallup-report-2017

Heathfield S.M., 2019 What Does Employee Involvement Actually Look Like? Retrieved fromhttps://www.thebalancecareers.com/employee-involvement-1918100

Kitto K., 2019. What's a Simple Definition of Employee Engagement? [Web blog post]. Retrieved from https://www.glintinc.com/blog/what-is-employee-engagement/

Morgan, J., 2017. Why the Millions We Spend on Employee Engagement Buy Us So Little. Harvard Business Review. Retrieved from https://hbr.org/2017/03/why-the-millions-we-spend-on-employee-engagement-buy-us-so-little

Rich B.L, Lepine J.A, Crawford E.R. (2010). Job engagement: Antecedents and effects on job performance. Academy of management journal.Vol.53, No.3 DOI:10.5465/AMJ.2010.51468988

Ryba, K. (2020). What is Employee Engagement? What, Why, and How to Improve It. Retrieved from https://www.quantumworkplace.com/future-of-work/what-is-employee-engagement-definition\#what-is-employeeengagement 
Schaufeli W.B., Bakker A. (2004). UWES Utrecht Work Engagement Scale Preliminary Manual[PDF file].Retrieved from https://www.wilmarschaufeli.nl/publications/Schaufeli/Test\%20Manuals/Test_manual_UWES_English.pdf

Sinclair, S. (2020). What is employee engagement? The long answer or the short answer [Web blog post]. Retrieved from https://www.talkfreely.com/blog/what-is-employee-engagement

Wigert B., Robson J. (2020). Remote Workers Facing High Burnout: How to Turn It. Retrieved from https://www.gallup.com/workplace/323228/remote-workers-facing-high-burnout-turn-around.aspx

White A. (2016). The Role of Engagement in Performance Management. Retrieved from https://www.aberdeen.com/hcmessentials/role-engagement-performance-management/ 